\title{
Laser direct writing of oxide structures on hydrogen-passivated silicon surfaces
}

\author{
Müllenborn, Matthias; Birkelund, Karen; Grey, Francois; Madsen, Steen
}

Published in:

Applied Physics Letters

Link to article, DOI:

10.1063/1.116823

Publication date:

1996

Document Version

Publisher's PDF, also known as Version of record

Link back to DTU Orbit

Citation (APA):

Müllenborn, M., Birkelund, K., Grey, F., \& Madsen, S. (1996). Laser direct writing of oxide structures on hydrogen-passivated silicon surfaces. Applied Physics Letters, 69(20), 3013-3015.

https://doi.org/10.1063/1.116823

\section{General rights}

Copyright and moral rights for the publications made accessible in the public portal are retained by the authors and/or other copyright owners and it is a condition of accessing publications that users recognise and abide by the legal requirements associated with these rights.

- Users may download and print one copy of any publication from the public portal for the purpose of private study or research.

- You may not further distribute the material or use it for any profit-making activity or commercial gain

- You may freely distribute the URL identifying the publication in the public portal

If you believe that this document breaches copyright please contact us providing details, and we will remove access to the work immediately and investigate your claim. 


\title{
Laser direct writing of oxide structures on hydrogen-passivated silicon surfaces
}

\author{
M. Müllenborn, ${ }^{\text {a) }}$ K. Birkelund, and F. Grey \\ Microelectronics Center, Technical University of Denmark, Lyngby, Denmark \\ S. Madsen \\ DME-Danish Micro Engineering A/S, Herlev, Denmark
}

(Received 7 June 1996; accepted for publication 11 September 1996)

\begin{abstract}
A focused laser beam has been used to induce oxidation of hydrogen-passivated silicon. The scanning laser beam removes the hydrogen passivation locally from the silicon surface, which immediately oxidizes in air. The process has been studied as a function of power density and excitation wavelength on amorphous and crystalline silicon surfaces in order to determine the depassivation mechanism. The minimum linewidth achieved is about $450 \mathrm{~nm}$ using writing speeds of up to $100 \mathrm{~mm} / \mathrm{s}$. The process is fully compatible with local oxidation of silicon by scanning probe lithography. Wafer-scale patterns can be generated by laser direct oxidation and complemented with nanometer resolution by scanning probe techniques. The combined micro- and nanoscale pattern can be transferred to the silicon in a single etching step by either wet or dry etching techniques. (C) 1996 American Institute of Physics. [S0003-6951(96)00646-8]
\end{abstract}

Hydrogen-passivated silicon surfaces have attracted much interest because of their well-defined state and bulklike surface reconstruction. They are used as starting layers for epitaxial growth and as resist layers for nanolithographic techniques, such as scanning tunneling, ${ }^{1,2}$ atomic force, ${ }^{3-5}$ and-most recently-scanning near-field optical lithography. ${ }^{6}$ This is because hydrogen-passivated silicon layers have ideal resist properties such as the possibility of depositing ultrathin layers $(<10 \mathrm{~nm})$ with good step coverage and high sensitivity to electrical currents and fields for pattern definition. The scanning probe techniques are based on the probe-induced removal of the hydrogen passivation and the subsequent oxidation of the exposed surface in air or another oxidizing atmosphere. The resulting oxide pattern is used as an etch mask.

One of the major problems of scanning probe lithography is the connection of the produced nanostructures to the macroscopic world. Both the fabrication of large patterns and the alignment of nanostructures to large patterns pose severe challenges to the serial scanning probe techniques with their often limited scan ranges, slow scan speeds, and low tolerance to surface steps.

Here, we report a new approach to optically generate wafer-scale oxide patterns on hydrogen-passivated silicon surfaces and analyze the physical mechanisms involved. The oxide patterns are detected by an atomic force microscope, which can be used to add features with sub-100 $\mathrm{nm}$ resolution to the optically defined pattern. A single etching step transfers the combined pattern into the silicon, which is a considerable simplification compared to approaches which require two different lithographic steps to define micro- and nanostructures, and which avoids the problem of scanning over steep edges during nanostructuring on photoresistdefined microstructures. ${ }^{7}$

The laser direct-write system used for the oxidation experiments consists of a continuous-wave argon ion laser with

${ }^{a)}$ Electronic mail: matthias@mic.dtu.dk
UV option, beam conditioning and focusing optics, and highresolution direct-current motor stages with internal encoders for sample translation. ${ }^{8}$ The system is designed to achieve minimum spot sizes and high-resolution positioning $(\sim 100$ $\mathrm{nm}$ repeatability) over large areas $\left(100 \times 100 \mathrm{~mm}^{2}\right)$. Typical achievable spot sizes are around $500 \mathrm{~nm}$ for $458 \mathrm{~nm}$ light. To generate a pattern, the beam is modulated on the fly using direct positioning pulses from the stages, while the substrate is translated with speeds of up to $100 \mathrm{~mm} / \mathrm{s}$.

For the experiments on amorphous silicon, substrates are thermally oxidized to a thickness of about $50 \mathrm{~nm}$ and covered with a boron-doped amorphous silicon $(a$-Si) layer, 10$100 \mathrm{~nm}$ thick and produced by direct current magnetron sputtering (Fig. 1). Substrates for the experiments on crystalline silicon are not pretreated. Before direct writing, the silicon samples are dipped in 5\% hydrofluoric acid for $60 \mathrm{~s}$ in order to strip the native oxide and passivate the surface. After exposure to laser light in air, the samples are either etched in $25 \%$ potassium hydroxide $(\mathrm{KOH})$ at room temperature for $30-270 \mathrm{~s}$, depending on the thickness of the $a-\mathrm{Si}$ layer, or transferred to an atomic force microscope (AFM) for further processing or for investigation of the grown oxide.

Exposure of the hydrogen-passivated silicon surfaces to laser light results in an oxide with a thickness comparable to

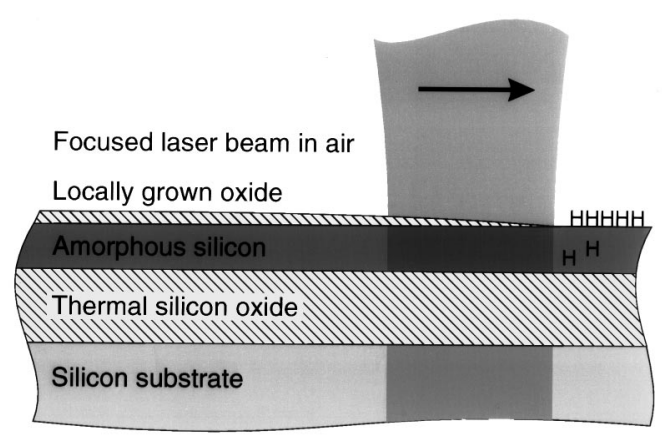

FIG. 1. Schematic of the laser direct write process. The $a$-Si layer is depassivated by the focused laser beam and oxidized after exposure to air. 
(a)
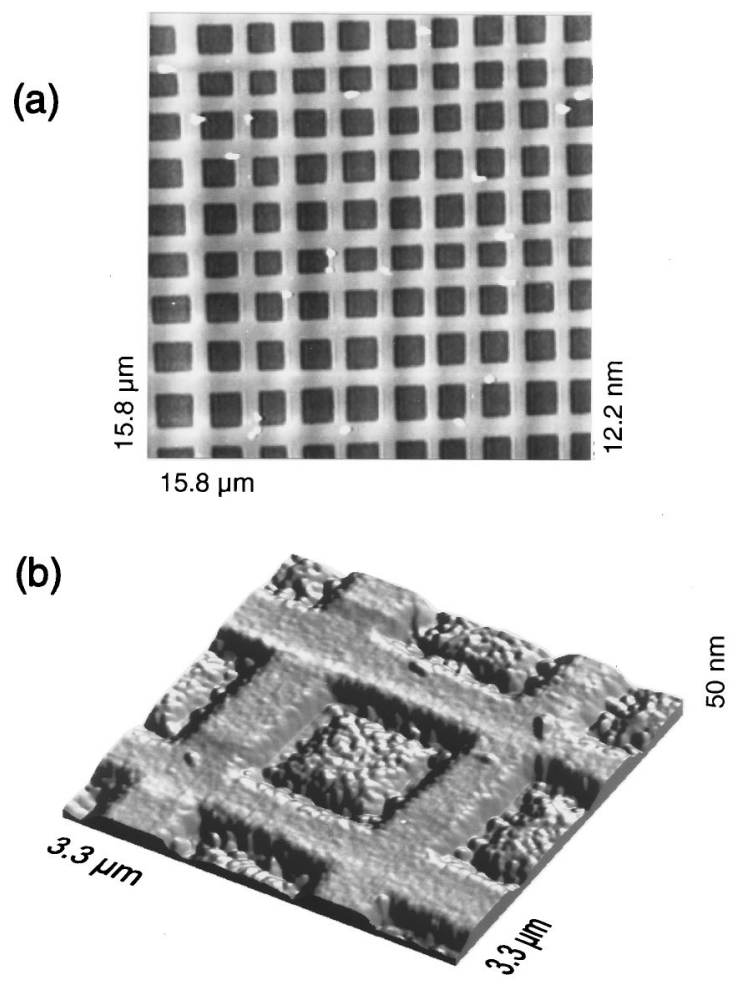

FIG. 2. AFM images of $a-\mathrm{Si}$ structures after $\mathrm{KOH}$ etching using a lasergenerated oxide mask. (a) Large area pattern in $10 \mathrm{~nm}$ thick $a$-Si on oxide, (b) close-up for $100 \mathrm{~nm}$ thick $a$-Si on oxide.

a native oxide, which suggests that hydrogen is desorbed by a photoinduced process similar to electrically induced desorption, followed by the oxidation of the depassivated surface. Optical desorption of hydrogen has first been reported by Kramer et al. for long exposure of passivated crystalline silicon to a static laser interference pattern. ${ }^{9}$ The optical desorption of hydrogen requires a minimum power density, which depends on substrate absorption, laser wavelength, and exposure time.

We have made quantitative desorption experiments on $10 \mathrm{~nm}$ thick $a$-Si on oxide by determining the threshold conditions for writing a test pattern (Fig. 2). Figure 3 shows the minimum power density required for the formation of an oxide layer sufficient to mask $10 \mathrm{~nm}$ of $a$-Si for $\mathrm{KOH}$ etching, as a function of exposure time. The corresponding minimum energy dose ranges from 0.02 to $20 \mathrm{~kJ} / \mathrm{cm}^{2}$ with the lowest dose required for the shortest exposure time. For all investigated wavelengths $(351,458,488$, and $514 \mathrm{~nm})$, the minimum power density remains constant for almost 3 orders of magnitude for exposure times between 0.1 and 100 $\mathrm{ms}$. Above $100 \mathrm{~ms}$, the minimum power density drops nearly linearly with exposure time, i.e., the minimum energy density is constant. For comparison, the dose and exposure time used by Kramer et al. ${ }^{9}$ is included in the figure. The change of slope in the time dependence suggests that more than one desorption mechanism is involved in the hydrogen desorption process.

Three mechanisms which are known to cause efficient hydrogen removal are thermal desorption, desorption by optically induced excess carriers, and direct optical interactions with surface atoms and molecules. Possible direct optical

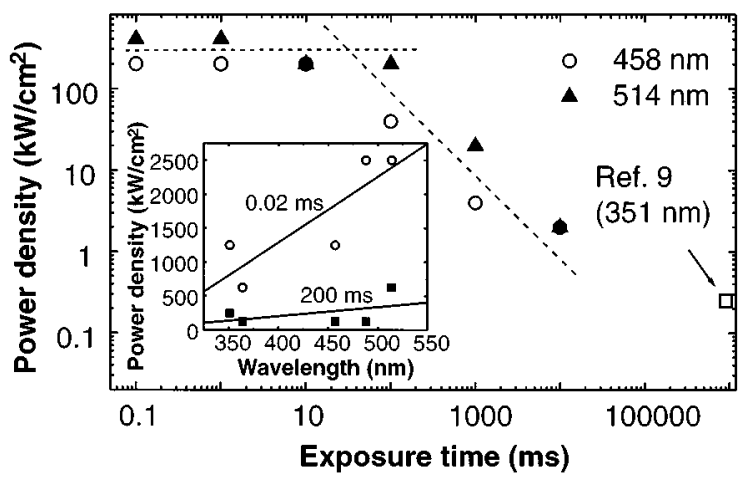

FIG. 3. Minimum power density for the optical desorption of hydrogen from the surface of a $10 \mathrm{~nm}$ thick $a$-Si layer as a function of exposure time for different laser wavelengths. The data point for $351 \mathrm{~nm}$ laser light is taken from Ref. 9. The inset shows the wavelength dependence of the minimum power density for two different exposure times.

processes include destabilization and dissociation of $\mathrm{Si}-\mathrm{H}$ bonds ${ }^{9}$ and excitation of adsorbed $\mathrm{OH}$ groups. ${ }^{10}$

In order to estimate the effect of thermal desorption, the laser-induced maximum temperature rise has been calculated assuming a Gaussian beam profile and cooling by threedimensional conduction into the substrate. ${ }^{11}$ The resulting temperature rise ranges from less than $1 \mathrm{~K}$ to almost $400 \mathrm{~K}$ for power densities between 2 and $200 \mathrm{~kW} / \mathrm{cm}^{2}$, respectively.

For short exposure times, the required power density is high enough to heat the substrate to the point of efficient thermal desorption of hydrogen at about $700 \mathrm{~K}$. In this regime, the writing speed can be increased to more than 100 $\mathrm{mm} / \mathrm{s}$ using a spot size of about $0.5 \mu \mathrm{m}$, allowing fast largearea direct patterning. Linewidths of down to $450 \mathrm{~nm}$ and line edges with radii of curvature of less than $20 \mathrm{~nm}$ have been measured by AFM imaging after $\mathrm{KOH}$ etching. The observed wavelength dependence of the minimum power density needed for patterning is similar to the wavelength dependence of the absorption coefficient of $a$-Si (Fig. 3, inset), in agreement with a thermally stimulated process.

At low power densities and long exposure times the calculated temperature rise is negligible. The mechanism in this regime is believed to be either an excited carrier process or a direct optical process. Both mechanisms can explain the enhanced hydrogen desorption observed for higher photon energies: The wavelength dependence can be a result of the absorption edge of $a$-Si for excited-carrier-induced desorption, ${ }^{12}$ and for direct optical dissociation the energy barrier can be in the range of $2.5 \mathrm{eV}$. No resonancelike behavior is observed in the wavelength dependence of the desorption process (Fig. 3, inset).

The compatibility of the laser direct write technique with STM and AFM lithography is demonstrated in Fig. 4. The images show two narrow leads connected to contact pads with a $2 \mu \mathrm{m}$ gap, written by laser direct oxidation. This gap has been bridged with a nanowire written by AFM lithography after detecting and aligning to the laser-generated oxide pattern. The AFM is run in contact mode in air using a titanium-coated silicon nitride tip and applying a voltage between $-5 \mathrm{~V}$ and $-10 \mathrm{~V}$ for oxidation. ${ }^{13}$ The entire process of defining contact pads and wires with an area of about 1 $\mathrm{mm}^{2}$ by laser direct writing and the $200 \mathrm{~nm}$ wide and $2 \mu \mathrm{m}$ 


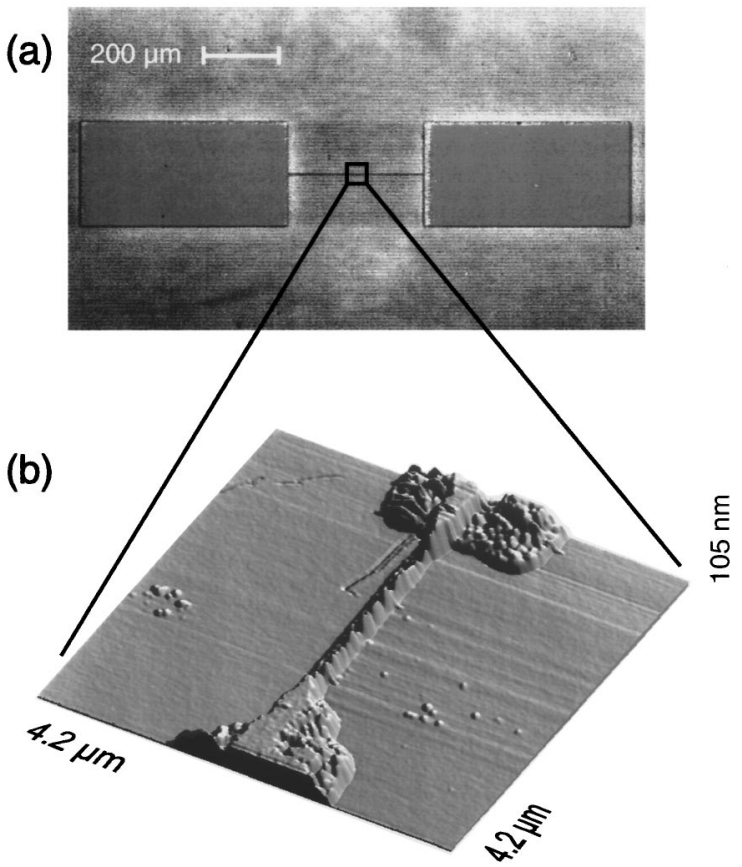

FIG. 4. (a) Optical microscope image of laser-defined contact pads with leads. (b) AFM image of an AFM-written nanowire bridging a $2 \mu \mathrm{m}$ gap between the leads from the contact pads, demonstrating the compatibility of AFM and laser oxidation. The oxide pattern has been used as a mask for $\mathrm{KOH}$ etching of a $100 \mathrm{~nm}$ thick $a$-Si layer, which is completely removed in the unoxidized areas.

long nanowire by AFM writing can be completed in less than $1 / 2 \mathrm{~h}$, which is fast enough to avoid substantial deterioration of the passivated surface in air.

Based on our results, several improvements and variations can be envisaged. While the locally grown native oxide in the presented experiments is only a moderate masking material, the oxide quality can be improved by desorbing hydrogen in a controlled oxidizing atmosphere at elevated temperatures. Using the optical desorption process for projection of masks would require very powerful or focused light sources since the required power density is very high compared to standard photoresist exposure. However, modified mask aligners or wafer steppers with increased UV illumination or focused light arrangements could reach the required power densities and make this process interesting for industrial applications. In particular, laser-based wafer steppers can deliver higher power densities in the UV range, which will drastically reduce exposure times as shown in Fig. 3. Sputtered $a$-Si layers can easily be deposited with a good step coverage and high uniformity on structured substrates, which is very interesting for pattern definition on bulk micromachined devices. Furthermore, $a$-Si can be patterned to a very high resolution, since it has an atomic granularity and a well-defined chemical composition.

In conclusion, we have shown that it is possible to locally oxidize hydrogen-passivated silicon surfaces by exposure to light with a photon energy above $2.5 \mathrm{eV}$. Different mechanisms play a role in the desorption process as a function of power density. Thermal desorption appears to be the dominant mechanism in the high power density range. This has been used to directly write patterns with scan speeds of up to $100 \mathrm{~mm} / \mathrm{s}$ with submicron resolution. The power density needed for desorption decreases with increasing exposure time above $100 \mathrm{~ms}$, which indicates a different desorption mechanism in this regime. For low power densities, the induced temperature increase is negligible, and direct optical or induced carrier processes are possible mechanisms. We show that laser direct writing of oxide structures is a particularly convenient complementary technique to scanning probe lithography on passivated surfaces, since it allows fabrication of large-scale connections to nanometer-scale circuitry, without increasing the number of processing steps.

${ }^{1}$ J. A. Dagata, J. Schneir, H. H. Harary, C. J. Evans, M. T. Postek, and J. Bennett, Appl. Phys. Lett. 56, 2001 (1990).

${ }^{2}$ E. S. Snow, P. M. Campbell, and P. J. McMarr, Appl. Phys. Lett. 63, 749 (1993).

${ }^{3}$ H. C. Day and D. R. Allee, Appl. Phys. Lett. 62, 2691 (1993).

${ }^{4}$ L. Tsau, D. Wang, and K. L. Wang, Appl. Phys. Lett. 64, 2133 (1993).

${ }^{5}$ F. Pérez-Murano, G. Abadal, N. Barniol, X. Aymerich, J. Servat, P. Gorostiza, and F. Sanz, J. Appl. Phys. 78, 6797 (1995).

${ }^{6}$ S. Madsen, M. Müllenborn, K. Birkelund, and F. Grey, Appl. Phys. Lett. 69, 544 (1996).

${ }^{7}$ S. C. Minne, H. T. Soh, Ph. Flueckiger, and C. F. Quate, Appl. Phys. Lett. 66, 703 (1995).

${ }^{8}$ M. Müllenborn, H. Dirac, and J. W. Petersen, Appl. Phys. Lett. 66, 3001 (1995).

${ }^{9}$ N. Kramer, M. Niesten, and C. Schöenberger, Appl. Phys. Lett. 67, 2989 (1995).

${ }^{10}$ D. Klyachko, P. Rowntree, and L. Sanche, Surf. Sci. 346, L49 (1996).

${ }^{11}$ M. Lax, Appl. Phys. Lett. 33, 786 (1978); using this calculation, the temperature rise for thick thermally insulating oxide layers is underestimated.

${ }^{12}$ First-principle density functional calculations show that there are no surface states in the band gap for fully hydrogen-passivated crystalline silicon surfaces [K. Stockbro (private communication)]. Also hydrogenated $a$-Si, which has been studied in detail and which is similar to hydrogenpassivated $a$-Si, does not show distinct absorption bands in the band gap [G. D. Cody, in Hydrogenated Amorphous Silicon, Part B, Optical Properties, edited by J. I. Pankove, Semiconductors and Semimetals, Vol. 21, edited by R. K. Willardson and A. C. Beer (Academic, Orlando, 1984), p. $11]$.

${ }^{13}$ K. Birkelund, M. Müllenborn, S. Madsen, and F. Grey, Superlatt. Microstructure (to be published). 